\title{
1. Introduction Making sense of the state: a political economy approach
}

Jean-Michel Josselin and Alain Marciano

\section{INTRODUCTION}

Even if mainly devoted to private law, the law and economics literature has certainly not neglected constitutional issues. In particular, the intricate relation between law and the state has been frequently analysed, either from a positive point of view or for normative purposes. Thus, vexed questions were raised as to the necessity to ground the legitimacy of the state on rules of law or, reciprocally, as to the need to justify law in the state. To provide tentative and partial answers to these questions, the different chapters that constitute this book employ the specific tools of a political economy approach. These will of course relate to the standard programme of constrained maximization, but in which 'institutions matter'. The first step is then the objective function. When organizing the seminars leading to this book, we manifestly did not have to be specific about an attachment to a democratic state as an objective. Strikingly, the contributors dealing with this foundational concern (how to shape a democratic state) all focused on the constraint which delineates the democratic state, namely the informational constraint. Publicity of law and of decisions, transmission, manipulation and creation of information are some of the many facets that contribute to the delicate balance between democracy as freedom and democracy as order (Part I). In this respect, law and lawfulness prove to be media as strong as they are to be handled carefully. Indeed, legal rules play a similar role as information, being in the same way the key to the foundation of a democratic state. However, the role of law and the institutional position of judges, crucially depend on how the democratic state is organized. In other words, the way democracy is defined influences the role that legal rules play (or have to play). All the contributions of the book that are dedicated to this question converge towards this necessary condition (Part II). Building on these pillars, the state can then make incursions into the markets. The control over the institutions governing competition requires a fine tuning of legal regulations. Public policies are to be interpreted here in the light of the first two 
parts of the book. The state can put forward and implement regulations in order to improve the circulation of relevant information on markets. It must do that under constraints meant to prevent incursions from becoming invasions. These usually self-imposed constraints on the domain of state intervention will have to serve Pareto improvements to the economy (Part III).

\section{HOW TO SHAPE A DEMOCRATIC STATE: THE INFORMATIONAL CONSTRAINT}

'Good' information can certainly enhance democratic virtues. 'Bad' information obviously impedes political competition. How do law, and more generally institutions, convey this informational constraint? What is the contribution of political economy to the definition of what is good or bad in this respect?

\subsection{Enhancing Democracy through Competitive Information}

To build and shape a democracy demands that constitutional and postconstitutional safeguards be carefully devised. In this respect, the status of information is of the utmost importance. Let us first take the example of a basic action in a democracy: voting is indeed a founding decision for individuals participating in a forum of collective action. In Chapter 2, Michael Wohlgemuth demonstrates how even at this stage the informational constraint does matter. There may have been a fallacy in considering Schumpeter as one of the founders of 'public choice'. The latter mostly rests on the Downsian spatial voting model, where citizens' preferences are given on the ideological space. Politicians adapt to it and, beyond rent-seeking and bureaucratic deviations, they more or less carry the will of the representative voter: 'However, by attaching high standards of rationality to political actors, by treating political issues and preferences as given and by modelling political competition as a state of affairs in which politicians passively adapt to a given majority will, much of public choice remains ironically close to rationalistic and idealistic traditions' (Wohlgemuth, this volume). This Hobbesian view of the likely Pareto improvement associated with a democratic state is dramatically challenged by the two hypotheses of the Schumpeterian theory. Here, political leadership replaces the search for the optimal location on the ideological space: 'democracy is competition for leadership and not for given voter distributions' (Wohlgemuth, this volume). The role of political leadership is all the more important that, as far as individual behaviours are concerned, Schumpeter departs from one of the core assumptions in 'standard' public choice theory, thereby 
anticipating recent developments in psychology, in assuming that the level of rationality typically drops when citizens enter the political field. To use a game-theoretic analogy, let us suggest that the Downsian message is carried out under assumptions of perfect information (the vote-maximizing politician is a 'position taker' as he/she would be a price taker on usual markets) or imperfect information (probabilistic voting being an example). On the contrary, the Schumpeterian vision of politics could be one of incomplete information where the types of voter are unknown. Political entrepreneurship then not only consists in discovering them, but also affects the formation of the individuals' political opinions. In other words, by creating political issues, entrepreneurs endogenize types of voters.

From this perspective, democracy is no longer viewed as a means to reach an equilibrium but has rather to be considered as a process in which individuals learn from others. As a consequence, truth emerges from and evolves through the confrontation of individual opinions; it thus will not be easily circumscribed (we shall come back to this later). On the other hand, the plasticity of individual beliefs (amounting to irrationality?) allows a politician to shape and select political preferences best suited for his/her own purposes. Much attention is thus paid to possible manipulation of information (Wohlgemuth 2002).

This view not only challenges the standard public choice approach, it is also provocative to our Cartesian minds! Nevertheless, the gap between the two visions may be bridged by recalling that the rationalistic and idealistic tradition can also account for endogenous types of voters. Although Chapter 3, by Eli Salzberger and Niva Elkin-Koren mainly aims at understanding the influence of the cyberspace information revolution on the theory of the state, it also provides a valuable reminder of a quite neglected aspect of the rational theory of the state. Thomas Hobbes, John Locke and John Rawls have taken on most of the theoretical landscape, leaving Rousseau ([1762] 1992) largely outside the economic interpretation of the state. This lapse is unfortunate since it could provide a track of reconciliation between the Austrian and Downsian views: 'Economic analysis à la Rousseau assumes that individual preferences are not exogenous, but endogenous to the political process. In other words, the difference between the General Will and the sum of the wills of the individuals can be presented as the result of changes of preferences, from self-regarding towards more cooperative, other-regarding and less conflicting preferences' (Salzberger and Elkin-Koren, this volume). Of course, as Salzberger and Elkin-Koren admit, the economic analysis of Rousseau still has to be carried out. Let us add that it may have significant consequences for constitutional economics.

What will remain of national constitutional law if cyberspace develops in non-territorial collective entities? Will the principle of personality 
supplant the principle of territoriality? Communication technology provides a means to easier consensus and enhances political participation. Cyberspace as a medium of information may 'compensate for the shift from unanimity to majoritarianism and from direct democracy to representative democracy' (Salzberger and Elkin-Koren, this volume). The relaxed informational constraint puts the deliberating process to the forefront; institutions and preferences would then be outputs of political participation. Quite strikingly, we are not very far from the French revolutionary debates on the relationship between democracy and participative education (Baczcko 1982). ${ }^{1}$ Individual preferences are once again endogenous to the political process, but in a Cartesian and not Schumpeterian framework.

As demonstrated by Salzberger and Elkin-Koren, the relationship between information technology and democracy is of utmost importance if one wishes to understand the evolution of institutions, and in particular constitutional law. It remains to further interrogate the interplay between values, information technology and the law. Salzberger and Elkin-Koren leave this to others, and Leonard Dudley takes on the task in Chapter 4. The idea is to get a long-term view on the spatial pattern of innovations. Stylized facts are quite impressive. The concentration of scientific discoveries between 1700 and 1850 in a handful of European countries (plus the United States) questions the role of geography and institutions. It can also be illuminated, and this is the heart of Dudley's thesis, by the container and the content of information. What is at stake is the explanation of the striking development gap between the different regions of Eurasia over the period. Communication technology is envisaged here as a combination of a medium (vernacular languages at that time, cyberspace dialect now?) and of a message (ideas competing as a result of political entrepreneurship à la Schumpeter or as the consequence of educative democracy à la Rousseau). If we go back to the problem of values, communication technology in its two dimensions produces constitutional systems which either help innovations thrive or smother them inexorably. We leave it to the reader to discover the extent to which differentiated development can be explained by the intertwined influences of medium and message. Lessons from the previous two chapters may hint at the benefits of standardized ways of communication. This is reinforced by the views of Hobbes and Rawls as far as the publicity of law is concerned (Josselin and Marciano 1995). However, this common or shared knowledge through the medium should not arise at the expense of the message. Competition on the market for ideas provides fertile soil for innovations to flourish. Standardization should not suppress the competitive qualities of free communication. Cyberspace must remain under close scrutiny to ensure that competing messages still circulate. 
In game-theoretic terms, Dudley shows that having the relevant information technology helps us both to avoid falling into chicken or prisoner's dilemma games and to reach a framework of an assurance game. This is also consistent with Rousseau's stag-hunt game, in which coordination of information as well as confidence in other players are sufficient conditions for Pareto improvements (Rousseau [1754] 1990). Freedom of speech thus seems to be a most important individual prerogative that may even have to be guaranteed by constitutional safeguards (Josselin and Marciano 2002a). But should we systematically take its value for granted?

\subsection{Endangering Democracy through Strategic Information}

When discussing the Schumpeterian message, we mentioned that the status of truth in politics is far from straightforward. This is the object of inquiry of Chapter 5, by Manfred Holler. Truth-telling, personal opinion, secrets, personal integrity in the face of public opinion, we are here again facing the dilemma of democracy as freedom and democracy as order. Holler builds on the dramatic history of George Orwell and his Cold War reverses. Game theory offers operational tools that help understand how individual reputation can be shaped by public opinion makers. All this would not be very interesting if the citizen involved - here Orwell and his collaboration with the Foreign Office's Information Research Department - were a standard player in a game of complete information. We pointed out before that politics is about incomplete information where the types of voter are unknown. When judging Orwell, public opinion makers also run their strategies in a world of incomplete information. The term 'judging' is intendedly ambiguous since '[t]he evaluation of public figures expresses social values and gives orientation to society and for this reason many legal systems contain, on the one hand, rules designed to protect the reputation of such personalities, but on the other permit the public dissemination of information about them and their private life' (Holler, this volume). The real Orwell may remain hidden but public opinion is provided with a revealed type consistent with collective beliefs.

The game-theoretic approach emphasizes the strategic nature of information, more precisely the strategic nature of its construction. If democracy is to build on discussion and debate, on progressively shared knowledge, then the strategic nature of truth may endanger it. If we add to the picture some propaganda combined with preference falsification (Kuran 1995), for instance, one may soon end up with a messy political landscape which stresses the pitfalls associated with endogenous locations of individuals in the ideological space. Political entrepreneurs and opinion makers may 
obviously get some profit by exploiting 'primitive' citizens (Schumpeter, quoted by Wohlgemuth, this volume). This positive account of the political arena is quite frightening, and the ensuing gloom may explain why on the normative side of the problem, one may wish to stick to the idealistic and rationalistic tradition of public choice. Holler's analysis nevertheless shows, in positive terms, how accurate the strategic approach is.

Leaving the Cold War behind us, information and opinion are again at stake in the case of what Bruno Frey and Simon Luechinger, in Chapter 6, label the curse of our times, namely terrorism. And if we leave history to study current events, we nevertheless face problems similar in many respects. Information in a framework of terrorism has many related dimensions: first of all, information about what terrorism is, what it costs to whom, and what its impact on individual utilities can be. To this must be added information about the consequences it has on the formation of opinion, both in the media and in the political arena. Hence the attempts at measurement that would help us understand in the most objective terms what the costs and benefits (if any) or losses of terrorism are. 'In any case, government policy against terrorism involves costs. It is therefore necessary to know the costs imposed on the people by terrorist activities. Only then can government decide what resources should be mustered to deal with terrorism. If the utility loss is underestimated, the government tends to undertake too little, and if it is overestimated, the government tends to overreact and activate too many resources' (Frey and Luechinger, this volume).

In the face of likely strategic behaviours with regard to the construction of information (exemplified in Holler's chapter), the question of measurement is all the more important in that it may help reduce informational biases, say between government and citizens. A straightforward instance would be the case of a political leader overestimating a threat in order to shift the attention of voters from problems other than terrorism (for example, unemployment or public deficits). Frey and Luechinger survey the various methods (contingent valuation, happiness functions and so on) offered by economic theory and they assess how they are or could be applied. Whatever their merits and drawbacks, those methods remain unconnected with the political arena, hence the proposition to put more emphasis on directly democratic procedures, like referenda, whenever fighting terrorism is involved. In many countries, this would require constitutional reform, and a shift of value from representative government to collective decision making in the political forum. As an innovative medium of communication, cyberspace may help to achieve this. It nevertheless remains to assess whether the message maintains its competitive properties and does not fall into the hands of political entrepreneurs or public opinion makers who could possibly display strategic behaviours. ${ }^{2}$ 
The informational constraint obviously shapes and delineates state prerogatives. Whenever information displays competitive properties, it enhances the goal and scope of democratic institutions; if it covers or allows strategic behaviours, then the 'true' purpose of democracy is somewhat blurred. In both cases, the question of control is relevant. This is manifest in the second case but no less necessary in the first one. Delegating power means entrusting part of individual natural rights to the sovereign. That the latter may be democratically elected does not change the nature of the 'delegation dilemma', as we may label it, although it may affect its magnitude. Let us see how the dilemma relates to democracy and legal rules.

\section{HOW TO CONTROL A DEMOCRATIC STATE: THE LEGAL CONSTRAINT}

Delegating power from the citizens to the state cannot be conceived without constraints that will help both develop and contain public prerogatives in reasonable limits. To reach this goal, to delineate the scope of government, legal rules are an undisputable theoretical prerequisite, but how are they worked out in practice? How do judges, experts and administrators contribute to the enhancement of democracy? Now, the legal system is part of a larger institutional framework. Therefore, as the developments of this part show, the practical answers envisaged and proposed to these questions depend on the institutions within which they are raised.

\subsection{Independence versus Discretion: Constitutional Regimes versus Monist Democracies}

Any individual endowed with the right and capacity to exercise power also benefits from the possibility to promote, or to utilize, rules to favour private interests. This is the delegation dilemma. The problem thus defined characterizes the paradoxical nature of power rather than reveals the flaws of a specific institutional structure. However, institutions are not without influence on the practical solutions that can be offered to solve the dilemma. From this perspective, it is important to keep in mind a usual distinction, recalled by Sophie Harnay in Chapter 9, between 'monist' and 'dualist' (or constitutional) democracies. ${ }^{3}$ The former type of democracy, thus named because of the uniqueness of the source of power, focuses on the legitimacy of public decisions. It is thus assumed that power has to rest, ultimately, in the hands of the citizens or in those of their direct representatives, the elected politicians. In this respect, judges, being non-elected agents and thus having received no prerogatives from the citizens, have to remain under 
the control of the elected politicians. Thus, the political review of judicial decisions is viewed as possible and also as desirable. But, and this is stressed as an important limit to monist democratic states, the increase in legitimacy of the decisions could be compensated by possible abuse of power. The delegation dilemma indeed seems particularly difficult to avoid when power rests in the hands of agents that no one appears to be in a position to control.

An alternative to monist democracies, dualist democracies or constitutional regimes insist on the necessity of controlling elected agents. 'Dualism' is thus used to designate regimes in which power, although having a unique source, is none the less separated and divided among different institutions. Separation and division of power ensure institutional competition but also guarantees that the same rules equally bind citizens and the government. A constitutional regime is thus based on the rule of law. It is then assumed that, under this condition, the arbitrary use of power by elected politicians cannot but be restricted. Then, dualism, as noted by Ackerman, views 'the courts as an essential part of a well-ordered democratic regime ... the courts serve democracy by protecting the hard-won principles of a mobilized citizenry against erosion by political elites who have failed to gain broad and deep popular support for their innovations' (1998, p. 10). In other words, a constitutional regime crucially depends on the possible judicial review of political choices. That judges are non-elected agents, and thus able to escape the control of the citizens, may generate losses in terms of legitimacy which are compensated by the gains that result from the containment of the delegation dilemma.

The possible gains due to an efficient control of the state are not only organizational but can also be evaluated in economic terms. From this perspective, in Chapter 7, Stefan van Hemmen and Frank Stephen survey the literature measuring the impact of legal rules and institutions on economic development. The evidence they provide is important since it sheds light on the importance of measurement when assessing the positive properties of alternative theories of the state and its organization. In this respect, their chapter is a matching piece to the analysis by Frey and Luechinger (the same remark can be applied to the chapter by Voigt, as will be seen later). Van Hemmen and Stephen analyse how financial laws and enforcement mechanisms both influence the development of financial markets, which in turn influences economic growth. Among the elements put forward in their presentation, one can mention the independence of courts and the weakness of state power. Therefore, an independent judiciary seems to be a decisive condition for economic development.

A similar argument as to the economic role of an independent judiciary is at the basis of Stefan Voigt's analysis in Chapter 7. In fact, in the first 
place, Voigt clearly, although implicitly, places his analysis within the framework of a constitutional regime. Then, building on authors such as Immanuel Kant or Friedrich Hayek, he argues that the rule of law is the basic condition for a just and efficient democratic - by which he means a dualist democratic - system. Judicial independence then appears as a practical institutional provision matching the theoretical prerequisite of a rule of law. Therefore, judicial independence has to be assessed and measured as precisely as possible in order to understand how it influences economic growth. However, the task is as important as it is difficult. Noting the discontent as to the standard criteria used to evaluate judicial independence, Voigt then suggests making the relationship between judicial independence and the rule of law empirically accessible by introducing two indicators. $\mathrm{He}$ proposes to distinguish between de jure independence, acknowledged by the constitutional documents, and an effectively respected de facto independence. The empirical studies, of which he presents the results, show that while de jure judicial independence does not have an impact on economic growth, de facto judicial independence positively influences real GDP growth per capita. To sum up Voigt's argument, judicial independence is a source of economic growth because it ensures that everyone will be bounded by the same legal rules. This argument confirms what is put forward by van Hemmen and Stephen in their analysis: the role of informal institutions is as important as the role of formal institutions even if 'more effort is needed to identify which formal (structure of the judicial system) and informal (levels of trust in the society) factors produce high enforcement' (van Hemmen and Stephen, this volume).

Nevertheless, a rule of law regime may suffer from certain flaws. Indeed, such regimes function correctly under the explicit condition that no one is in a monopolist position, providing him/her with the possibility of controlling the provision of law; that is, if and only if judges do not replace politicians as monopolists. This is acceptable from the perspective of the bottom-up logic of a legal system in which judges are not considered as the creators of legal rules. The role of judges then consists in clarifying imprecise and ambiguous rules in order to improve coordination among individuals. Within such legal systems, judges are assumed to act only as arbitrators whose task is to discover the rules resulting from the repeated interactions that take place between individuals. As arbitrators, judges therefore do not stand in the position of a monopolist, a central authority benefiting from coercive powers in the provision of law. They rather act on behalf of all the society members. As we have shown elsewhere (Josselin and Marciano 1995, forthcoming), the judge is the agent of the impartial spectator of the common law, in the sense given by Adam Smith and David Hume. Ormrod expresses a similar view when he notes the English predilection for the 
'fantasy of the judge as a detached observer, reaching inevitably right conclusions by processes of impeccable logic, in conformity with the decisions of others' (1987, p. 125). This quotation gives a perfect summary of the virtues of a system based on the rule of law: being in the hands of 'detached observers', the rules are impersonal, general and are applied regardless of any specific circumstances. They are thus devoid of any arbitrary character. Now, there are many circumstances in which judicial decision making not only amounts to choosing a point from a set of given alternatives. There are indeed many circumstances in which, being in an 'open area' (to use Richard Posner's terms), judges are obliged to create rules because there is no rule to discover and no legal material to help them in rendering their decision. In other words, it seems impossible to envisage a legal system complete enough to avoid the manipulation of legal rules by the individuals effectively granted with the right to create them. This does not mean that judges - like elected politicians - are malevolent but they cannot be considered only as the impartial spectators of the common law (see also Josselin and Marciano 1997). This observation implies three different and complementary conclusions.

First, the fantasy of a system in which judges are only 'detached observers' is rather optimistic and cannot but be, as Voigt notes, an ideal difficult to actually reach. Second, even a regime based on the rule of law must envisage institutional provisions to control the behaviour of judges. Thus, as Voigt comments, beyond judicial independence, other criteria have to be respected: 'laws need to be general, abstract, and certain . . . procedural safeguards such as the prohibition of retroactive legislation, habeas corpus, proportionality and the like need to be in place. If all this is not the case, even a factually independent judiciary will not turn an arbitrary regime into one belonging to the family of rule of law regimes' (Voigt, this volume). Third, the vulnerability of a constitutional regime to the manipulation of rules by independent judges legitimates the comparison with a monist regime: are regimes in which political review of judicial choices is possible so vulnerable to delegation dilemmas? This question is at the core of Sophie Harnay's chapter.

Using the theoretical reference of Hans Kelsen, rather than that of Kant or Friedrich von Hayek, Harnay develops her analysis within the framework of a monist democracy. She thus assumes that a legal decision can always be replaced by a political choice because the norms produced by (democratically) elected politicians are higher than any other, in particular legal, norm. Therefore, de jure judicial independence is not guaranteed. Harnay develops an analysis which parallels Voigt's argument. Using a game-theoretic model, she demonstrates that discretionary power, that is de facto independence, is possible even in a regime which like, monist democracies, does not guarantee de jure independence. In fact, judges benefit from 
a discretionary power which is induced by the institutional structure. ${ }^{4}$ The practical consequence of this situation is that judges utilize their discretionary power to protect the interests of the citizens. An illustration is then provided showing how French administrative judges, a particularly good example of dependent judges, systematically tend to favour citizens. Interestingly, a system in which judges remain structurally dependent from political decision makers has the same virtues as a dualist, constitutional regime. This is certainly one of the reasons explaining the not so bad ranking of France in Voigt's evaluations.

\subsection{The Political Role of Administrations, Experts and Judicial Power}

The models of democracy discussed in the two preceding chapters relate to contrasted modes of social regulation. Rule of law regimes are associated with spontaneous social orders and regulation is assumed to depend on market criteria: The customary foundation of rules is assumed to avoid the arbitrary and discretionary use of power by politicians. By contrast, monist democracies build upon the tenets of social contract and trust the criteria of political regulation. Thus, as said earlier and described in Harnay's chapter, the promoters of monist democracies state that, in spite of the hierarchy which exists between political and legal norms, judges none the less utilize their discretionary power to control politicians and defend the citizens' rights. This particular form of social regulation, based on a mix of legal and political rules, is part of a heritage typical of the French institutional structure. These characteristics have been incorporated in the French democratic state through a progressive accumulation of legal and political reforms, the most important of which was the creation of the Civil Code at the beginning of the eighteenth century (see Josselin and Marciano 2002b) or the reform of the Council of State at the end of the nineteenth century (Harnay and Marciano 2001). In Chapter 10, Christian Barrère interprets this model of regulation with regard to the principles of the French Revolution and the social contract theories. In a normative analysis which complements the positive developments made by Voigt or Harnay, Barrère not only stresses the role that judges have to play in social regulation, he also states that the criteria which guide judicial organization ought to be different from and larger than those used by market regulation. To some extent, Barrère goes beyond the usual distinction between constitutional regimes and monist democracies. Indeed, while he explicitly rejects market-based regulation, he implicitly refuses the pre-eminence of political criteria over those of judges. Judicial regulation would lie beyond market and political regulation. Then, we are left with a crucial question: where does the legitimacy of judicial choices come from? Barrère argues that 
judges must to be trusted as 'wise persons, deciding in the name of the French people' (this volume). Thus, wisdom legitimates judicial decision making. Although the argumentation developed by Barrère does not make reference to that literature, it is certainly possible to refer to wisdom as a kind of intrinsic motivation upon which one can rely to justify judicial choices. It none the less remains that no one can ascertain the rightness and the efficiency of these decisions since wisdom conveys self-justification. Let us then focus on efficiency.

Wisdom may not mean expertise. Judges may well contribute to democracy and promote order by improving social regulation, but their decisions may not be efficient for all that. Are judges able to separate welfareimproving from welfare-reducing projects? Or, to put the question in more precise terms: is the possible judicial control of the decisions made by public administration economically valuable for the society? This is the issue analysed by Georg von Wangenheim in Chapter 10. This, once again, is related to the delegation of decision making in a democracy. Indeed, in von Wangenheim's chapter, the question amounts to the economic legitimacy to authorize the substitution of decisions made by non-elected experts with choices of democratically elected non-experts. The model thus proposed leads to the conclusion that, even if courts have less expertise than public administrations and even if courts are more likely to approve welfare-reducing projects and to reject welfare-enhancing projects, the judicial control of administrative decisions may be welfare improving. Two reasons can be mentioned as explanations for this result. First, the lack of expertise of judges may be compensated by the information they infer from the appeal process. Second, potential judicial review plays the role of an incentive mechanism on administrators, thus inducing them to choose a better project in the first place. Even if they are not 'detached observers', judges promote more efficient public decisions, ex ante through incentives towards public administration and ex post through information revealed during the process of judgment.

In market-based economies, revelation of information rests on (imperfectly) competitive patterns of interactions. These interactions involve individuals as well as judicial and governmental institutions. Whether the political market works at equilibrium (the public choice approach) or as a search process (the Schumpeterian approach) does not fundamentally change the imperfect but competitive nature of the norms upon which law is organized.

In a planned economy, the legal constraint would be easily endogenized by the power in place. The latter will use it to serve its own purposes. In market-based economies, however, the legal framework remains a constraint instead of becoming an instrument. The democratic state must then 
build on 'good' information and on the rule of law to serve the purposes of the citizens.

\section{THE STATE AT WORK: REGULATION AND PUBLIC POLICIES UNDER INFORMATIONAL AND LEGAL CONSTRAINTS}

State intervention on markets can take many forms and obey various motives, from Pareto improvements to the promotion of private interests. Part III focuses on regulation and public policies for which informational and legal constraints are 'binding'.

\subsection{Incursion into or Invasion of Markets: Fine Tuning Public Regulation}

As shown by the preceding discussion, most of the contributions to this volume consider 'information' as a key element for a democracy. Therefore, unsurprisingly, misused information may shake the foundations of a democratic state. The necessity of avoiding a strategic and opportunistic use of information then provides a first justification for public intervention. Besides a correct use of information, the proper functioning of a democracy also requires a correct (not to say optimal) amount of information. For instance, economic development, as Dudley showed in Chapter 4, depends on an efficient informational technology. Moreover, the capacity of judges to promote just ('wise', in Barrère's terms) and welfare-improving projects depends on the information they have, as is stressed in von Wangenheim's chapter. If one adds the frequent statement that information is a public good, there may be another point in favour of state intervention, in order to guarantee an optimal provision of information. Hence, the not so unusual arguments among economists that the provision of information per se should be submitted to public regulation. ${ }^{5}$

Among the rules aimed at organizing the provision of information, copyright laws are usually put forward - in particular by lawyer economists - as necessary. The argument is that in the absence of property rights on ideas or information, individuals are denied the basic incentives they need to innovate. In other words, public regulation should be justified as a means to promote competition in the provision of information. Although correct, this statement also seems partial. Indeed, and this is the argumentation developed by Giovanni Ramello in Chapter 12, copyright legislation gives birth to many unexpected and overlooked side-effects. Thus, Ramello questions the standard analysis about the economic legitimacy of copyright laws in showing that these laws tend to negatively affect the functioning of 
the two sides of the market, limiting the demand and promoting the concentration of information in the hands of a limited number of individuals. Hence, the seemingly justified though radical conclusion: 'copyright today does not seem able to pursue the public goals that justify its existence, although it certainly does succeed in serving private interests. The former are, at best, manipulated in order to achieve the latter' (Ramello, this volume). Therefore, in contrast to what is usually assumed, copyright law would not promote competition and economic efficiency. One could envisage a second type of justification to possible control on the provision of information, namely organizational efficiency or the stability of social order. From this perspective, legal scholars as well as many economists have insisted upon the necessary regulation of information in order to avoid a possible decrease in the quality of information and the subsequent threats to social order. Hence there is a possible trade-off between two seemingly contradictory aspects of regulation, stability and competition: rules that promote stability are frequently detrimental to competition.

Public regulation in the banking sector faces a similar problem. This is the issue discussed by Donatella Porrini and Giovanni Ramello in Chapter 13. Their analysis starts from the particularly vivid tension which exists in the regulation policy in the banking sector between the promotion of stability and that of competition. Historically, antitrust rules in the banking sector have been shaped in order to obey the demands of stability, 'relegating competition to second place' (Porrini and Ramello, this volume). Therefore, 'the banking market becomes extremely rigid on the supply side and structurally not equipped for a competitive orientation, and banks come to occupy a privileged position vis-à-vis governments that - to a greater or lesser extent, depending on the countries and the situations enables them to sidestep the antitrust authorities' (ibid.). Therefore, according to the authors, it seems impossible to reconcile stability and competition under the heading of standard antitrust banking legislation. Their argument is that regulation of banking activities from the perspective of the supply side must not be abandoned but has to be completed by rules which could favour competition through the demand side of the market, by enhancing consumer mobility. Porrini and Ramello then suggest that this objective could be reached by reducing the switching costs that currently restrict the mobility of consumers between different banks.

Regulation of information is thus at the heart of market regulation. Public policies nevertheless must make sure that such interventions do not generate strategic rather than competitive information. This responsibility must be borne not only for current and immediate situations, but also across generations, which we shall consider now. 


\subsection{Art and Heritage: The Social Contrivance of State Intervention}

We have already made a number of incursions into history but without really taking into account the simple fact that 'each and every today is followed by a tomorrow'. In other words, we have not yet taken into account the generational and hence intergenerational nature of a number of public policies. The previous quotation is from Samuelson (1958, p. 482) and it works as a preamble to his now standard result according to which the first theorem of welfare economics does not hold in overlapping generations models. Money or the social contract are thus ways of ensuring 'collective collusion' in order to guarantee that a minimal link does exist from one generation to another. As is clear from the last two chapters of this book, preservation of patrimonial resources appear to sometimes require public intervention (Chapter 14 by Paolo Figini and Laura Onofri) or avoid it (Chapter 15 by Jürgen Backhaus) in order to transmit our heritage to the next generations.

Figini and Onofri examine the market for Old Master paintings. Using the hedonistic methodology, they identify the shadow prices of the characteristic of these art objects and further consider the role of the policy maker in the regulation of such a specific market. Faced with an instant demand that in some occasions will not hesitate to use illegal means (and take advantage of a flexible budget constraint), the regulator may be tempted to use law in order to pre-empt art objects. Purchase (legal or illegal) by private amateurs would indeed deprive future generations of the public good properties of art. The legislator may then use the social contrivance of legal rules (the authors consider here the Italian case, which can easily be extended to other countries). For instance, private collectors are submitted to strict rules of notification. As is too often the case with public incursions into markets, the good intention paves the way to hidden information and black markets. The recommendation to open official markets to more competition and less regulation would indeed serve instant efficiency but may at the same time threaten intergenerational equity. The chapter thus illustrates the ambiguous role of information that was stressed previously in this volume. It also points to the fact that the provision of intergenerational public goods such as works of art requires the conception of a legal constraint which can at the same time be coercive and not lead to the withholding of information from official channels of circulation.

The inability of governments to preserve intergenerational public goods reflects the standard failure of competitive markets emphasized by Samuelson. The bitter irony conveyed by the last chapter of this volume serves as a reminder that the imperfection of competition should not lead us too far in condemning it. Backhaus indeed shows how a government can 
avowedly decide not to provide intergenerational public goods in order to reshape public opinion. In a way, this brings us back to a drastic extension of Holler's chapter. Backhaus takes the example of the extensive disinvestment in the former communist countries. The decay in historical heritage and historical sites should not be attributed to a sheer neglect in upkeep. The intended destruction of such public goods (and of all the shared knowledge they convey) has the purpose of 'uprooting' people, in order to make them 'fungible' in state socialist society. Once again, the informational (through propaganda) and legal (through nationalization) constraints can be as many weapons in the hands of governments whose goals are not necessarily those of the people they represent.

\section{CONCLUSION}

This volume demonstrates that the relationship between law and the state has two fundamental dimensions. The first one relates to the making of the information of both citizens and government. The second one deals with the legal structure that will help both develop and contain public prerogatives. The contributions to this book have given sometimes contrasted views on these two points. In many respects, however, they all point to the same requirement: that the ongoing making of democracy must retain information and legal structures as endogenous variables in the political process. As long as these variables are present in the collective forum, one may hope that the balance will be kept between democracy as order and democracy as freedom.

\section{NOTES}

1. Jean-Michel Josselin would like to thank Max Leguem for pointing out how the French revolutionary debates helped shape the reflection on the links (through education) between citizenship and rational behaviour.

2. Rousseau ([1755/1758] 1990) has a strikingly similar credo when he writes 'La patrie ne peut subsister sans la liberté, ni la liberté sans la vertu, ni la vertu sans les citoyens; vous aurez tout si vous formez des citoyens' (pp. 77-8): The Homeland cannot survive without liberty, nor liberty without virtue, nor virtue without citizens; you will have the whole if you educate the citizens (our translation).

3. The terms 'monist' and 'dualist' are borrowed from Ackerman (1998). To be more precise, the advocates of dualist democracies prefer using the label 'constitutional regimes' to insist on the role of the constitution as a binding rule and also to make clear the difference from a monist democratic regime where the delegation dilemma is unavoidable. As Voigt notes in his chapter, 'Logically, a rule of law constitution does not imply that the political system be democratic' (Voigt, this volume).

4. Or 'structure-induced discretionary power' (see, among others, Steunenberg 1996; Schmidtchen and Steunenberg 2003). 
5. Interestingly, as noted by Ronald Coase, economists, even when they are favourably disposed towards market competition, tend to defend the necessity to regulate the provision of ideas.

\section{REFERENCES}

Ackerman, Bruce (1998), We the People, Vol. 1. Foundations, Cambridge, MA: Belknap Press.

Baczko, Bronislaw (1982), Une éducation pour la démocratie [An Education for Democracy], Paris: Garnier.

Harnay, Sophie and Alain Marciano (2001), 'Independence and judicial discretion in a dualist regime: the case of the French administrative judiciary', in Bruno Deffains and Thierry Kirat (eds), Law and Economics in Civil Law Countries, Greenwich, CT: JAI Press, pp. 243-55.

Josselin, Jean-Michel and Alain Marciano (1995), 'Constitutionalism and common knowledge: assessment and application to a future European constitution', Public Choice, 85: 173-88.

Josselin, Jean-Michel and Alain Marciano (1997), 'The paradox of Leviathan: how to develop and contain the future European state', European Journal of Law and Economics, 4: 5-21.

Josselin, Jean-Michel and Alain Marciano (2002a), 'Freedom of speech in a constitutional political economy perspective', Journal of Economic Studies, 29: 324-31.

Josselin, Jean-Michel and Alain Marciano (2002b), 'The making of the French Civil Code: an economic interpretation', European Journal of Law and Economics, 14: 193-203.

Josselin, Jean-Michel and Alain Marciano (forthcoming), Administrative law and economics', in Jürgen G. Backhaus (ed.), The Elgar Companion to Law and Economics (second revised and enlarged edition), Cheltenham, UK and Northampton, MA, USA: Edward Elgar.

Kuran, Timor (1995), Private Truth, Public Lies, Cambridge, MA: Harvard University Press.

Ormrod, R. (1987), 'Judicial discretion', Current Legal Problems, 40.

Rousseau, Jean-Jacques ([1754] 1990), Discours sur l'origine et les fondements de l'inégalité parmi les hommes (Discourse on the origin and foundations of inequality among men), Paris: Garnier-Flammarion.

Rousseau, Jean-Jacques ([1755/58] 1990), Sur l'économie politique; considérations sur le gouvernement de Pologne; projet de constitution pour la Corse [Discourse on Political Economy; Considerations on the Government of Poland; Constitutional Project for Corsica], Paris: Garnier-Flammarion.

Rousseau, Jean-Jacques ([1762] 1992), Du contrat social (A treatise on the social contract), Paris: Garnier-Flammarion.

Samuelson, Paul (1958), 'An exact consumption-loan model of interest with or without the social contrivance of money', Journal of Political Economy, 66: 467-82.

Schmidtchen, Dieter and Bernard Steunenberg (2003), 'European policymaking: an agency-theoretic analysis', in Alain Marciano and Jean-Michel Josselin (eds), From Economic to Legal Competition: New Perspectives on Law and Institutions 
in Europe, Cheltenham, UK and Northampton, MA, USA: Edward Elgar, pp. 143-63.

Steunenberg, Bernard (1996), 'Agent discretion, regulatory policymaking, and different institutional arrangements', Public Choice, 86: 309-39.

Wohlgemuth, Michael (2002), 'Democracy and opinion falsification. Towards a new Austrian political economy', Constitutional Political Economy, 13: 223-46. 